\title{
A hegemonia da burguesia industrial brasileira: o caso do ensino técnico profissional (1930- 1950)
}

\author{
Talita F. Bordignon ${ }^{1}$ \\ Eraldo Leme Batista ${ }^{2}$
}

\section{Resumo}

No presente artigo, analisa-se como a burguesia industrial brasileira organizou-se, entre 1930 e 1950, em torno da criação de estratégias que lhe permitiram não apenas fomentar a industrialização do país, como também implementar seu ideário político-econômico. A criação do Instituto de Organização Racional do Trabalho - IDORT e do Serviço Nacional de Aprendizagem Industrial - SENAI, representam importantes passos para a garantia da hegemonia burguesa. Também avalia como os acordos bilaterais firmados entre Brasil e Estados Unidos para a educação técnica industrial permitiram a interferência dos EUA em assuntos brasileiros. Os argumentos pautam-se em publicações do IDORT e no Decreto-Lei n.9.724/1946 por meio do qual firmou-se o primeiro dos acordos bilaterais mencionados.

Palavras-chave: História da Educação; Educação Profissional; Ensino Industrial; Industrialização.

La hegemonia de la burguesia brasileña: el caso de la educación profesional (1930-1950)

\section{Resumen}

En el presente artículo, se analiza la forma en la que la burguesía industrial se organizó, entre 1930 y 1950, alrededor de la creación de estrategias que le permitieron no solamente fomentar la industrialización del país, sino también implementar su ideario político económico. La creación del Instituto de Organización Racional del Trabajo (IDORT) y del Servicio Nacional de Aprendizaje Industrial (SENAI) representa un importante paso hacia la garantía de la hegemonía burguesa industrial. Asimismo, evalúa cómo los acuerdos bilaterales para la educación técnica industrial, firmados entre Brasil y Estados Unidos, permitieron la interferencia de los estadounidenses en asuntos brasileños. Los argumentos se basan en publicaciones de IDORT y en el Decreto Ley No. 9.724/46, a través del cual se firmó el primero de los acuerdos bilaterales.

Palabras clave: Historia de la Educación; Educación Profesional; Educación Industrial; Industrialización.

\section{Introdução}

A análise de como se formam os operários que alimentam a totalidade do mundo do trabalho é fundamental para a compreensão de como se coloca a organização social no modo de produção capitalista. O desenho que caracteriza a hierarquização social sob os ditames do capital é determinado pela hegemonia que exerceram determinadas frações de classe. Ora, os

\footnotetext{
${ }^{1}$ Universidade Federal de Goiás (UFG), Goiânia, talitabordignon@ufg.br.

${ }^{2}$ Universidade Federal Rural do Rio de Janeiro (UFRRJ), Rio de Janeiro, eraldolbatista@gmail.com.
} 
industriais se utilizaram das mais variadas estratégias para garantir a perpetuação deste modelo social hierárquico e, dentre elas, figura o processo formativo das classes trabalhadoras. $\mathrm{O}$ ensino de um determinado tipo de comportamento aos trabalhadores, enquanto se preparam para o trabalho na fábrica, é uma das táticas que visam a manutenção da ordem.

Sob este ponto de vista é que se devem pensar as táticas dos industriais brasileiros entre as décadas de 1930 e 1950. As elites industriais brasileiras, responsáveis pelo projeto de organizar o trabalho a partir de uma perspectiva cientificista, inspiraram-se nas experiências de empresários paulistas nas estradas de ferro, particularmente na Companhia Estrada de Ferro Sorocabana. A organização científica do trabalho pautava-se, sobretudo, na adequação do trabalhador aos recém-implementados métodos de trabalho, bem como às tecnologias que começavam a ser utilizadas, como a substituição do vapor na geração de energia pela tração elétrica, mais vantajosa por representar maior produtividade com menor custo e mais segurança.

Ou seja, a compreensão de como se mantiveram como grupos hegemônicos neste período explica os métodos que foram aplicados nas escolas técnicas industriais brasileiras. $\mathrm{O}$ objetivo deste ramo de ensino pode ser sintetizado numa formação acrítica para os trabalhadores que, por sua vez, acabaram se transformando num apêndice das máquinas, tal como na proposta do taylorismo, que invadiu a vida dos trabalhadores sob todos os aspectos.

\section{Presença do taylorismo na sociedade brasileira: da indústria à vida privada}

$\mathrm{O}$ taylorismo era visto, em princípios do século $\mathrm{XX}$, como a base em que se assentava a solução para os problemas sociais e econômicos do país. A ideia de organizar o trabalho segundo seus princípios ganha força e passa a ser perseguida como meta pela elite industrial brasileira.

Da crescente admiração dos industriais brasileiros por Taylor e seus ideais de racionalização do trabalho, nasce, em princípios dos 1930, o Instituto de Organização Racional do Trabalho - IDORT, cujo projeto de padronizar as estratégias de produção para aumentá-la e, ao mesmo tempo, reduzir custos, mostra-se uma eficaz forma de, também, disciplinar e controlar os trabalhadores, a quem eram oferecidas formações no sentido de que produzissem mais e de modo mais eficiente, sem acidentes e desperdícios. O que se assistiu, no entanto, foi a expansão dos princípios tayloristas das fábricas para outros aspectos da vida. O empresário Roberto 
Simonsen foi um dos defensores da racionalização da sociedade como um todo, para além do aperfeiçoamento dos métodos de trabalho e da seleção profissional por meio da administração científica. Essa última era apresentada por ele nos seguintes termos:

[...] a redução dos custos de produção não se faria à custa de [...] salários, mas antes por meio de uma 'máxima eficiência do trabalho', que seria obtida com uma 'perfeita organização na qual, por disposições inteligentemente adotadas, as perdas de tempo e os esforços não-produtivos sejam reduzidos ao mínimo'. [...] os verdadeiros princípios de cooperação cordial entre patrões e operários iriam predominar, em função dessa 'perfeita organização' (SIMONSEN apud CUNHA, 2005, p.31).

Na mesma linha de defesa de uma suposta cooperação entre classes, o editorial do número 4 da Revista IDORT, intitulado "Esprit de corps", discorria sobre a necessidade de o trabalhador envolver-se com seu ofício de forma solidária como meio essencial de se atingir a eficiência no chão da fábrica. De acordo com a publicação,

Um dos factores mais decisivos na efficiência da organização de um trabalho coletivo - embora frequentemente esquecido ou desprezado - é o que os francezes chamam 'esprit de corps' e que poderíamos traduzir livremente por 'espírito de solidariedade'. Todo conductor de homens, isto é, todo chefe de serviço deve estimular o desenvolvimento desse estado psychologico entre os seus subordinados. Os empregados e operários que trabalham conscientemente sob a acção desse estado de espírito serão sempre os melhores auxiliares e os mais productivos. $O$ 'esprit de corps' é a comprehensão, por parte de cada indivíduo de uma organisação determinada, de sua 'funcção' no conjuncto, isto é, da influência de sua actuação particular nos resultados do todo. Para se chegar a esse estado de espírito é necessário um trabalho preparatório bem coordenado, corroborado por actos e factos de evidente significação, partidos do centro, ou melhor, da direcção da empreza (REVISTA IDORT, 1932c, p.1).

Ou seja, a preocupação com o curso da industrialização no país demonstrava o interesse dos industriais brasileiros diante da otimização da produção: adequar-se ao desenvolvimento capitalista na condição de periferia do sistema. A burguesia industrial esteve empenhada, portanto, em adotar os métodos e processos próprios da organização racional nas fábricas numa forma de estar em comunhão com o que ocorria a nível internacional. Desta feita, o discurso a ser inculcado à classe trabalhadora passava pelo argumento de que todos fazem parte de um mesmo corpo - harmônico se cada qual desempenhar a sua função. 
É preciso considerar também que a participação do Estado foi essencial para consolidar um processo de industrialização fortemente atrelado a um conjunto de ações dedicadas à educação do novo trabalhador, como a criação, em 1942, do Serviço Nacional de Aprendizagem Industrial (SENAI). Embora sustentassem convicções diversas, militares, burocratas civis e, obviamente, a elite industrial aliaram-se no sentido de delegar ao Estado a promoção do programa de industrialização. De acordo com Fausto (2011, p.201):

\begin{abstract}
A burocracia civil defendia o programa de industrialização, por considerar que ele era o caminho para a verdadeira independência do país; os militares porque acreditavam que a instalação de uma indústria de base fortaleceria a economia [...] os industriais, porque acabaram se convencendo de que o incentivo à industrialização dependia de uma ativa intervenção do Estado.
\end{abstract}

O projeto de industrialização do país não tomou em consideração a desigualdade social, nem concebeu ações relevantes com o objetivo de mitigá-la ou, ao menos, minimizá-la. A base do programa era a racionalização do trabalho, a qual seria plenamente atingida se o trabalhador tivesse disciplina e espírito de colaboração. O discurso sobre a viabilidade de todos os aspectos da sociedade, e não apenas o trabalho, serem geridos com base na lógica da organização racional tornou-se hegemônico nos meios responsáveis pela implantação do parque industrial brasileiro, nomeadamente entre intelectuais do IDORT, que acreditavam que a extensão daquela lógica ao Estado levaria a que transpusesse o espaço fabril e fosse incorporada ao cotidiano das pessoas.

Postos em prática, esses ideais foram fundamentais para neutralizar a luta de classes, haja vista que, pela via da desqualificação do discurso das lideranças operárias, cooptaram os trabalhadores para uma sociedade (aparentemente) sem conflitos, instando-os a colaborar com as classes dominantes no que Ihes foi apresentado como um projeto comum da sociedade brasileira: o progresso, o desenvolvimento e a organização racional do trabalho e da sociedade. Como partes de um mesmo organismo social, os trabalhadores deveriam unir-se à elite industrial em prol do desenvolvimento da sociedade. Amplamente inscrito nos debates, o clichê da pertença a algo maior (a pátria, a sociedade) esvaziou o sentido de diferença de classes e, logo, também o de luta entre elas:

[...] Não se comprehende que, num paíz como o Brasil, pleno de recursos 
inexplorados, gastemos intelligencia, tempo e energia em discussões estéreis e em luctas internas, que só nos prejudicam e nos enfraquecem diante de outros povos unidos e organismos na fortíssima concorrência internacional (AZEVEDO, 1932, p.37).

O excerto acima, retirado de artigo publicado na revista do IDORT, é de autoria de um dos fundadores do Instituto, o engenheiro e industrial Aldo Mário de Azevedo, e permite que se tenha ideia da tônica dos discursos que advogavam a existência de uma pretensa sociedade de cooperação entre classes sociais. Por vias como essas, rearticulou-se o espaço fabril e educou-se "o operariado segundo os princípios da ética do trabalho para consolidar o projeto hegemônico da burguesia industrial" (PICHELLI, 1997, p.77).

No plano político, o ano de 1930 destaca-se pela efervescência provocada pela crise da sucessão de Washington Luís à presidência da República e pelo decorrente golpe de Estado que conduziu Getúlio Vargas ao cargo de mandatário da nação. No período conhecido como Era Vargas, entra em vigor uma série de medidas trabalhistas, como a criação, ainda em 1930, do Ministério do Trabalho, Indústria e Comércio, a que sobrevieram importantes deliberações, como a regulamentação da jornada de trabalho na indústria e no comércio, e a regulamentação da mão-de-obra da mulher e de menores de idade. Se a criação desse Ministério marca, por um lado, a série de determinações que criavam e protegiam os direitos dos trabalhadores, por outro, abre o precedente para um efetivo controle das questões trabalhistas por parte do Estado. Em 1932, foram criadas as Juntas de Conciliação e Julgamento, pari passu com o projeto da elite industrial de mitigar disputas trabalhistas entre operários e patrões. Nessa direção, vários decretos entram em vigor com o fito de controlar a atividade dos sindicatos, até então sob forte influência de imigrantes com vivência prévia em embates trabalhistas em seu país de origem. A minuciosa regulamentação dos direitos dos trabalhadores protege-os do arbítrio do patrão, mas, simultaneamente, torna desnecessária a ação dos sindicatos e esvazia-lhes o papel classista e de luta. Essa era uma reivindicação da elite industrial, disposta a arcar com os custos que a nova legislação trabalhista traria em troca de neutralizar a, até então, contundente ação sindical nas disputas entre empregados e patrões.

$\mathrm{Na}$ esteira do estrangulamento do perímetro de atuação sindical, sobrevém a cassação do direito à greve. Em 1932, o Decreto-lei no 21.396 (BRASIL, 1932) previa a punição de grevistas 
e a expulsão do país de trabalhadores estrangeiros em greve; três anos mais tarde, em 1935, a Lei de Segurança Nacional (BRASIL, 1935) tipificaria a greve como delito e, em 1937, a Constituição outorgada do Estado Novo estabeleceria, em seu artigo 139, que a greve e o lock out eram "recursos anti-sociaes, nocivos ao trabalho e ao capital e incompatíveis com os superiores interesses da produção nacional" (PORTO, 2012, p.86).

A série de medidas vai ao encontro das ideias propaladas pela elite industrial, em especial pelos empresários ligados ao IDORT que, como mencionado, procuravam convencer a classe trabalhadora de que os diferentes estratos não constituíam classes sociais, mas partes de um mesmo organismo vivo, as quais deveriam agir em cooperação umas com as outras: "Os brasileiros ainda não se compenetraram da luta e não se convenceram da necessidade inadiável de união, cooperação, de colaboração e de disciplina. Assistimos diariamente às mais estéreis discussões e lutas entre partes do organismo vivo que é a nossa pátria (Revista IDORT, 1932b, p.1).

\section{Elite industrial e educação profissional}

Conforme mencionamos, a educação do trabalhador foi um dos flancos elementares por onde a elite industrial brasileira logrou atingir a meta de formar quadros de profissionais capacitados para lidar com as novas tecnologias que vinham assumir, na economia, o papel que fora das atividades rurais. Ao mesmo tempo, esses novos trabalhadores tinham de ser formados no espírito de cooperação que animava o projeto de industrialização do país.

Roberto Mange, líder do movimento pela administração científica do trabalho, foi o intelectual orgânico responsável por desenvolver as experiências racionais na formação do operariado. Afinado com o taylorismo, Mange gozava de prestígio junto aos educadores escolanovistas ${ }^{3}$ de destaque na época, como Lourenço Filho, Fernando Azevedo e Anísio Teixeira - signatários do Manifesto dos Pioneiros da Educação Nova. O IDORT foi fundamental para a discussão e reorganização do ensino profissional no Brasil. Durante o Estado Novo (1937-1945),

\footnotetext{
${ }^{3}$ A Escola Nova surge, na Europa, em fins do século XIX. No Brasil, ganha força a partir de 1932, quando da elaboração e divulgação do Manifesto dos Pioneiros da Educação Nova. A nova Educação assentava-se nos princípios da laicidade e da gratuidade, de forma a que se garantisse que o acesso à Educação não seria vetado pela condição financeira.
} 
seus membros conseguiram encaminhar, e fazer que fossem regulamentadas, propostas que regiam a implantação do ensino profissional.

É importante observar aqui o que previu um dos artigos do Decreto-lei no 4.073 de 30 de janeiro de 1942, sobre o ensino industrial:

Art. 67 - O ensino industrial das escolas de aprendizagem será organizado e funcionará, em todo o país, com observância das seguintes prescrições:

I - O ensino dos ofícios, cuja execução exija formação profissional, constitui obrigação dos empregadores para com os aprendizes, seus empregados.

II- os empregadores deverão, permanentemente, manter aprendizes, a seu serviço, em atividades cujo exercício exija formação profissional.

III. As escolas de aprendizagem serão administradas, cada qual separadamente, pelos próprios estabelecimentos industriais a que pertençam, ou por serviços, de âmbito local, regional ou nacional, a que se subordinem as escolas de aprendizagem de mais de um estabelecimento industrial.

IV- As escolas de aprendizagem serão localizadas nos estabelecimentos industriais a cujos aprendizes se destinam, ou na sua proximidade (BRASIL, 1942).

Por seu turno, o Serviço Nacional de Aprendizagem Industrial - SENAI - surge em consequência da entrada em vigor do Decreto-lei no 4073/42:

A implantação do sistema SENAI foi muito rápida e conseguiu logo o reconhecimento dos industriais e do governo por sua eficiência, prontamente exigida na conjuntura da Segunda Guerra Mundial. Muitos produtos manufaturados, antes importados, tiveram de ser produzidos internamente, exigindo esforço sem precedentes em projetos, improvisação de equipamentos e formação de força de trabalho. Devido à dificuldade de importação de componentes, a manutenção dos equipamentos exigiu operários qualificados em quantidades crescentes (CUNHA, 2000, p.55).

Criado por decreto governamental, mas mantido com capital privado, o SENAI é uma instituição ambígua, dado que as esferas pública e privada interpenetram-se em sua gestão. 0 fenômeno, conforme Cunha (2000, p.45), é "constante na Educação brasileira, embora o modo como [essas esferas] se interpenetram tenha variado". Como contrapartida às indústrias por assumirem a educação profissionalizante, o Estado assinou contratos e convênios com organismos internacionais, tornando propícia a veiculação do capital nacional privado ao capital internacional. Ainda conforme Cunha (2000, p.46), trata-se de uma relação pautada no 
"corporativismo como forma de dominação". Tais pressupostos nada tinham em comum com os princípios escolanovistas, então defendidos por muitos intelectuais idortianos, como se pode verificar em Muller (2008, p.144):

[...] Por meio de um discurso embasado nas "competências técnicas", a elite industrial considerava que a formação profissional deveria ser preparada através de métodos racionais e científicos, limitada à necessidade das indústrias e que somente aqueles "mais aptos" seriam efetivamente aproveitados. Portanto, o discurso da competência técnica tornava a educação profissionalizante um assunto de interesse exclusivo da indústria, e não ligada a objetivos educacionais mais amplos ou aos direitos dos trabalhadores. Assim, propostas para uma formação profissional universal deveriam ser descartadas por serem irracionais e extravagantes, já que o número de aprendizes seria definido pela demanda empresarial, aliado a um funil que se iniciava com os testes psicotécnicos e se estreitava na dura realidade diária da formação, dividida entre a escola e o trabalho nas oficinas.

A pedagogia do mais apto, afinada com os princípios tayloristas, era aplicada por meio de métodos que mecanizavam o aprendizado e neutralizavam as hipóteses de criticidade por parte do educando. Um desses métodos, largamente utilizado pelas escolas do SENAI, eram as chamadas Séries Metódicas de Aprendizagem dos Ofícios $(\mathrm{SMO})^{4}$, que consistiam em fragmentar o conteúdo que se pretendia ensinar em etapas. O sistema mostrou-se eficaz em formar eficientes executores de comandos, inaptos, todavia, a encarar criticamente o trabalho que realizavam.

Em conformidade com os princípios do Training Within Industry (TWI), um programa de treinamento industrial desenvolvido nos Estados Unidos durante a Segunda Guerra Mundial, as SMO aparecem assim descritas em uma publicação da United States Agency for International Development (USAID) uma das agências norte-americanas de financiamento:

Como instruir

Primeiro Grau: Preparar o trabalhador - Colocá-lo à vontade. Descrição do trabalho e apuração do que o empregado já conhece a respeito do assunto. Despertar o interesse de aprender o ofício. Enquadramento do empregado em

\footnotetext{
${ }^{4}$ As primeiras SMO foram introduzidas em algumas empresas ferroviárias como a Companhia Paulista de Estradas de Ferro, a Sorocabana e a Mogiana, "que matriculavam alguns jovens na Escola Profissional Mecânica, onde se formavam e voltavam a trabalhar nas respectivas estradas." (DIAS et al., 1992, p.57). Depois, paulatinamente, as SMO penetraram nas instituições de ensino industrial no Brasil.
} 
posição correta.

Segundo grau: Apresentação da Operação. Dizer, mostrar e ilustrar um assunto importante de cada vez. Acentuar a importância de cada ponto-chave. Instruir com clareza, de forma completa e com paciência, dentro dos limites da compreensão individual.

Terceiro grau: Experimentar a Execução - Mandá-lo fazer o trabalho, corrigindo os erros. Fazê-lo explicar todos os pontos-chaves das operações à medida que repete o trabalho. Certificar-se do que ele entendeu. Continuar até você ter certeza de que ele aprendeu.

Quarto grau: Orientar - Deixá-lo orientar-se. Indicar a quem se dirigir para pedir ajuda. Fazer verificações frequentes. Encorajar a formulação de perguntas. Diminuir gradativamente a tutela excessiva e muito insistente.

SE O TRABALHADOR NÃO APRENDEU, FOI O INSTRUTOR QUEM NÃO ENSINOU (USAID, 1965, p.146, destaque em maiúsculas do autor)

O ensino por meio das SMO dava-se em espaços que procuravam aproximar-se o mais possível do ambiente fabril. Além disso, o método de ensino, fragmentado, simulava as linhas de produção. Conforme Cunha (2000, p.76), o sucesso do sistema SENAI de ensino deveu-se a essa proximidade entre a sala de aula e a fábrica que, para além de garantir que o educando aprendesse o seu ofício, conduzia-o "a uma acomodação ao status de operário e de conformismo com a ordem social". Nesse sentido, o SENAI obteve êxito no projeto de formar mão-de-obra qualificada para a nova indústria brasileira, isto é, em conformidade com os princípios tayloristas. Tais princípios eram ensinados tanto com relação ao ofício que o aprendiz realizaria mais tarde, quanto também em relação à postura que deveria assumir no ambiente de trabalho e na vida.

A estratégia do SENAI para garantir que os quadros profissionais fossem constituídos por profissionais afinados com os ideais preconizados pela elite industrial foi investir na educação de jovens aprendizes, oriundos de classes pobres, a quem eram pagas bolsas de estudos para frequentarem seus cursos. Apresentavam-se aos estudantes os cursos existentes - que eram elaborados conforme as necessidades da indústria - e mostrava-se aos estudantes que aprender um ofício industrial e seguir os ditames da ética do trabalho racional eram sua única chance de sucesso na sociedade. Picheli $(1997$, p.39) analisa os preconceitos do empresariado em relação aos trabalhadores - eram considerados "doentes, improdutivos, ignorantes, indisciplinados" tornando evidente o porquê de os cursos profissionais serem estruturados para irem além de ensinar um ofício técnico: era preciso incutir nos aprendizes o sentido de lealdade ao sistema e, para isso, tinham que ser educados para que não fossem capazes de valorar o próprio trabalho, 
nem dar-se conta de sua importância no sistema produtivo.

\section{A burguesia industrial e sua articulação com o capital internacional}

A partir do final da II Guerra Mundial, as nações acompanham o clima belicoso entre Estados Unidos e a então União das Repúblicas Socialistas Soviéticas (URSS), que instaurou a chamada Guerra Fria, caracterizada por assentar-se no temor do perigo iminente de um conflito armado de proporções capazes de destruir o mundo inteiro. A estratégia adotada pelos americanos foi a de fazer o mundo crer que o comunismo era a pior ameaça que pairava sobre todos os países e que a URSS tencionava dominar o mundo, "sempre disposta a derrubar os reinos de liberdade" (HOBSBAWM, 1994, p.229). O capitalismo, representado pelos Estados Unidos, surge como único meio capaz de manter a salvo a democracia. A indústria cultural foi utilizada à exaustão para criar, no imaginário de mais de uma geração, a ideia de que capitalismo e democracia eram sinônimos e de que comunismo era sinônimo de ditadura. Mesmo quando a maior parte do Ocidente encontrou-se sob ditaduras capitalistas, essa ideia não se dissolveu e persiste até os dias atuais.

Era preciso, portanto, combater o inimigo comum e os Estados Unidos investiram em programas e em ações para minar qualquer possibilidade de regimes socialistas instalarem-se fora da URSS, sobretudo nos seus vizinhos da América Latina.

As agências que financiavam os acordos bilaterais entre os Estados Unidos e os países parceiros foram projetadas para fazerem germinar nessas sociedades a ideologia capitalista fortemente atrelada a um ódio cego ao comunismo. As novas relações de poder que se configuraram no pós-Guerra e que levaram à Guerra Fria tinham relação direta com o fato de que o país norte-americano firmara-se como potência econômica. Para exercer o domínio que a posição exigia, era preciso que as relações de dependência entre as nações também fossem reconfiguradas, daí o largo investimento dos Estados Unidos em ações para o desenvolvimento de seus parceiros.

Nesse contexto, o movimento nacional-desenvolvimentista toma corpo no país e a classe trabalhadora, após 1945, começa a clamar por direitos. Sob o populismo de Vargas, os trabalhadores viram serem implantadas suas maiores conquistas, como a Consolidação das leis 
do trabalho (CLT) e a fixação de um salário-mínimo vigente em todo o território nacional. Foi a chamada "política de massas", graças a qual, conforme Octávio lanni (1975), possibilitou-se efetivar no país o desenvolvimento industrial. Segundo lanni,

Por meio das técnicas jurídicas e políticas inerentes ao populismo, manteve-se em nível adequado ao progresso industrial a relação entre o custo de vida e salário real. Em âmbito mais largo, foi a democracia populista que propiciou a conciliação de interesses em benefício da industrialização e em nome do desenvolvimento nacionalista [...] (IANNI, 1975, p.61, grifos do autor).

Embora as medidas populistas de Vargas tenham representado importantes conquistas dos trabalhadores, a política de massas responsável por sua implantação tinha "conotação essencialmente desenvolvimentista"; isso significa que nunca houve uma real preocupação com o bem-estar do trabalhador mas, sim, com a necessidade de se criarem mecanismos que fomentassem o desenvolvimento do mercado interno a ponto de ser possível prescindir de recorrer à ajuda financeira internacional. Para tanto, era imperioso garantir o poder de compra aos assalariados; por outras palavras, era uma questão de se assegurar que "as relações de produção [estivessem] em conformidade com as exigências do desenvolvimento econômico" (IANNI, 1975, p.62). As políticas trabalhistas, que pareciam focadas em proteger o trabalhador, foram implementadas para que o nacional-desenvolvimentismo pudesse vingar.

A primeira estratégia nesse sentido, como se disse, foi fortalecer o mercado interno para que se fizesse desnecessário recorrer à ajuda internacional. A ideia, no entanto, não se sustentou por muito tempo e o país encontrou na articulação do capital nacional com o estrangeiro uma saída para manter o desenvolvimento.

Durante o governo de Eurico Gaspar Dutra (1946-1951), a defesa de uma política de associação ao capital externo começou a ganhar força e, ao final do segundo governo de Vargas (1951-1954), “o confronto entre os vários projetos de desenvolvimento econômico e de organização do poder torna-se crucial" (IANNI, 1975, p.68). Conforme Ianni (1975), em 1954, o antagonismo entre os que desejavam o desenvolvimento internacionalizado, isto é, associado a organizações exteriores, e os que pretendiam que o desenvolvimento econômico fosse acelerado de forma independente, era total.

Os planos e ações dos governos, entre as décadas de 1940 e 1950, passaram a basear-se 
na meta do desenvolvimento, que fez pressupor um sistema de segurança nacional organizado e unificado:

As ajudas internacionais estabelecidas mediante cooperação financeira, cooperação técnica, assistência econômica e programas assistenciais foram ficando cada vez mais imprescindíveis na relação entre as nações, e particularmente nas relações entre os países centrais e aqueles que se integraram retardatariamente ao processo de industrialização. Esses países, como o Brasil, necessitaram incorporar tecnologia estrangeira para iniciar o seu passo decisivo na constituição de uma economia capitalista através de uma modernização ancorada na urbanização e na industrialização [...] (NOGUEIRA, 1998, p.73).

O ímpeto da industrialização, aliado à suposta ameaça representada pelo Comunismo guiou muitas ações dos governos, haja vista serem aliados das burguesias locais. Nos anos 1960, o então embaixador americano no Brasil, Lincoln Gordon, embora reconhecesse o desenvolvimento tecnológico atingido pela URSS, desqualificava seu sistema de governo e denunciava práticas desumanas de trabalho, sem mencionar que essas mesmas práticas ocorriam no capitalismo:

É possível que certos aspectos do desenvolvimento soviético impressionem - a ciência e a educação técnica soviéticas, as usinas siderúrgicas, os foguetes nucleares e os satélites espaciais. Mas, quererá alguma nação livre construir sua indústria com trabalho forçado e coletivização e inanição de seus camponeses? Sujeitar-se-ia de boa vontade algum povo livre ao terror desumano que por 27 anos substituiu a crença em Deus pela crença em Stalin, agora denunciado por seus sucessores e cujo corpo foi removido do túmulo de Lenine talvez para dar lugar a algum outro dirigente deificado? (GORDON, 1962, p.12).

Nesse período tem-se os primeiros esforços dos Estados Unidos no sentido de interferir na política social e econômica dos países da América Latina. A Educação mostrou-se um dos caminhos mais fáceis para moldar as mentalidades à semelhança do que desejavam.

Em 1946, o Ministério da Educação e Cultura (MEC) firmou convênio com a InterAmerican Educational Foundation (IAF), por meio do suporte garantido pelo Decreto-Lei no 9.724, de 3 de Setembro de 1946 (BRASIL, 1946). O convênio previa que se realizasse um programa de cooperação mútua para o desenvolvimento da educação industrial-vocacional. 0 MEC investiu cem mil dólares no programa, gastos em cooperação com a IAF. A transparência 
do uso da verba poderia ser demonstrada em relatórios que seriam confeccionados se necessário. Uma comissão específica foi formada, a Comissão Brasileiro-Americana de Ensino Industrial (CBAI), subordinada aos dois governos, americano e brasileiro, com a missão de executar as ações necessárias para o desenvolvimento do projeto de aperfeiçoamento do ensino industrial.

Na década de 1940, a IAF funcionava como repartição corporativa do governo americano e, na década seguinte, foi substituída pelo Institute of Inter-American Affairs, que assumiu a área de acordos de cooperação internacionais. Presentemente, a IAF atua em diversos países da América Latina e no Caribe fomentando ações relacionadas à agricultura sustentável e à segurança alimentar; desenvolvimento de capacidades profissionais e empreendedorismo; Educação; engajamento cívico e liderança; direitos humanos e inclusão social; administração de recursos naturais e alternativas para a violência e para a imigração irregular. Essas informações, que podem ser encontradas no site da agência, evidenciam a continuidade de programas com forte tônica de interferência em temas políticos, sociais e econômicos dos países ditos periféricos.

Neste contexto, a posição dos economistas latino-americanos e estudiosos da Comissão Econômica para a América Latina e o Caribe - CEPAL, constituída em 1948 por decisão da Assembleia Geral das Nações Unidas, foi importante no sentido de que a CEPAL lançou-se em resposta às reivindicações dos países latino-americanos, que se diziam preteridos em favor dos países europeus, cuja reconstrução após a II Guerra foi encampada pelo Plano Marshall.

A CEPAL pautava suas análises dos problemas econômicos latino-americanos no contraste centro-periferia. No entanto, enquanto nos países centrais a maior parte dos trabalhadores estava integrada ao que se considerava moderno, na periferia, a realidade era outra. Destarte, conforme Bielschowsky (2000, p.42), esse modelo de acumulação "tinha efeitos sociais desagregadores, porque tendia a marginalizar mesmo os agentes econômicos com maiores potencialidades produtivas" como o Brasil, posicionado à periferia do sistema.

O economista brasileiro Celso Furtado teve importante atuação na CEPAL entre 1949 e 1957, como diretor da Divisão de desenvolvimento. Furtado, que em 1959 participaria da criação da SUDENE, a Superintendência para o desenvolvimento do Nordeste, pensou o desenvolvimento do Brasil "como a luta do Homem pelo controle do próprio destino e a acumulação como o vetor material que impulsiona o desenvolvimento" (SAMPAIO JÚNIOR, 
2008). O economista nordestino analisou os problemas brasileiros em relação ao centro do sistema, porém, sem ignorar a América Latina, cujas economias subdesenvolvidas caracterizavam-se pela exportação de matérias-primas e importação de industrializados. Pesava, ainda, o fato de que as burguesias nacionais dos países periféricos impuseram um padrão de consumo segundo o qual um restrito grupo, economicamente privilegiado, tinha acesso aos mais variados bens, enquanto os proletários não tinham poder de compra para gozar do mesmo acesso. Assim sendo, as elites locais tinham padrão de vida similar ao dos países centrais, estratégia com que se logra perpetuar as relações de dominação e dependência, típicas do capitalismo em desenvolvimento.

[...] A permanente introdução de novos produtos e novas formas de consumo é condição sine qua non para a reservação das formas sociais que caracterizam o sistema capitalista. [...]. Se, nos países desenvolvidos, o fluxo de novos produtos e o complexo de inovações tecnológicas que os acompanham são essenciais ao funcionamento da economia capitalista, no âmbito mundial tais fatores operam no sentido de preservar as relações de dominação e dependência que caracterizam a atual economia internacional [...] (FURTADO, 1972, p.13).

Ainda que os acordos bilaterais internacionais viessem sob a égide de fomentar o desenvolvimento do Brasil - e dos demais países periféricos geridos por capital internacional - o fato é que o esforço desenvolvimentista nunca teve por meta destruir as relações de dominação e de dependência dos países periféricos em relação aos centrais, e das massas trabalhadoras em relação às classes burguesas e às elites locais de seus países.

\section{Conclusões}

A elite industrial brasileira, muito bem-organizada, pôs em prática, de modo sistemático e planejado, ações de cooptação da classe trabalhadora para o ideal desenvolvimentista. 0 ensino técnico industrial foi uma das ferramentas mais eficazes para atingir esse objetivo. Para além disso, essa elite aliou-se ao capital internacional e consentiu que a interferência dos países estrangeiros extrapolasse as questões econômicas e se ingerisse na cultura e nas relações sociais, sempre apoiados na Educação e no ensino técnico, que refletia os anseios da burguesia para o mundo do trabalho. 
A formação de aprendizes por meio de uma metodologia de racionalização comportava também o aprendizado da postura e de uma determinada maneira de ser do trabalhador. Podese dizer que o SENAl e as Séries Metódicas Ocupacionais obtiveram êxito com aquilo a que estavam comprometidos naquele momento histórico: formar mão de obra qualificada para o setor industrial, mas sem preocupação com a formação humana, em sentido amplo. O objetivo perseguido foi o ideal formativo que molda os indivíduos pensando neles como extensões de máquinas, não humanos.

Entre as décadas de 1930 e 1950 muito se desenvolveu na intenção de qualificar trabalhadores de acordo com o que se esperava para as fábricas. Para os senhores, seria um incômodo sem precedentes conviver com operários que pensavam por si mesmos, ou que estivessem dispostos a subverter a ordem imposta pelo patrão. Todas as qualidades buscadas nos operários estavam de acordo com o contexto que se vivia na época - o clima gerado pela Segunda Guerra Mundial favoreceu a indústria moldada pelos interesses do capital. Ora, se fosse necessário demonizar quaisquer ideologias que pudessem pôr à prova a proposta liberal do capitalismo, então que fosse feito: daí a articulação entre as burguesias e a penetração do capital internacional nos negócios internos. A grande questão aqui é, portanto, que com os convênios bilaterais chega uma carga cultural que, embora não declarada, estivera prevista. 0 modelo de vida americano preconizado pelo bloco capitalista na Guerra Fria só encontrou como solução destruir a alternativa socialista.

Era necessário suprir a mão de obra nas indústrias, mas não de qualquer forma; ou seja, não eram bem-vindos todos os tipos de personalidades e comportamentos, principalmente aquelas que pudessem estremecer os ímpetos do sistema capitalista. Daí a opção por interferir na formação da classe trabalhadora desta forma e com estes métodos.

\section{Referências}

AZEVEDO, A. M. Organisar. Revista IDORT, São Paulo, n.3, p.5-7, mar. 1932.

BIELSCHOWSKY, R . Os anos 1960: redistribuir para crescer. BIELSCHOWSKY, R. (org.). Cinquenta anos de pensamento na CEPAL. V. Trad. Vera Ribeiro. Rio de Janeiro: Record, 2000, p.36-44. 
BRASIL. Decreto-Lei no 12.396, de 12 de maio de 1392. Institui comissões mistas de conciliação e dá outras providências. Diário Oficial da União: República Federativa do Brasil: Poder Legislativo: Rio de Janeiro, RJ, 16 mai. 1932. Disponível em: https://www2.camara.leg.br/legin/fed/decret/1930-1939/decreto-21396-12-maio-1932526753-publicacaooriginal-1-pe.html. Acesso em 21 set. 2021.

BRASIL. Lei n. 38, de 04 de abril de 1935. Define crimes contra a ordem política e social. Diário Oficial da União: República Federativa do Brasil: Poder Legislativo: Rio de Janeiro, RJ, 28 jun.1935. Disponível em: https://www2.camara.leg.br/legin/fed/lei/1930-1939/lei-38-4-abril1935-397878-republicacao-77367-pl.html. Acesso em: 06 abr. 2020.

BRASIL. Decreto-lei n. 4.073, de 30 de janeiro de 1942. Lei orgânica do ensino industrial. Diário Oficial da União: República Federativa do Brasil: Poder Legislativo: Rio de Janeiro, 09 fev. 1942. Disponível em https://www2.camara.leg.br/legin/fed/declei/1940-1949/decreto-lei-4073-30janeiro-1942-414503-publicacaooriginal-1-pe.html. Acesso em: 06 abr. 2020.

BRASIL. Decreto-Lei n. 9.724, de 3 de setembro de 1946. Aprova o acordo celebrado entre o Ministério da Educação e Saúde e a Inter-American Educational Foundation Inc., sobre educação industrial vocacional, e dá outras providências. Diário Oficial da União: República Federativa do Brasil: Poder Legislativo: Rio de Janeiro, 06 set. 1946. Disponível em: https://www2.camara.leg.br/legin/fed/declei/1940-1949/decreto-lei-9724-3-setembro-1946458393-publicacaooriginal-1-pe.html. Acesso em 06 abr. 2020.

CUNHA, L. A. O Ensino profissional na irradiação do industrialismo. São Paulo: Editora da UNESP, 2000.

CUNHA, L. A. O ensino de ofícios nos primórdios da industrialização. São Paulo: Editora da Unesp, 2005.

DIAS, J. J. A. et al. O giz e a graxa: meio século de educação para o trabalho. São Paulo: SENAI, 1992.

FAUSTO, B. História concisa do Brasil. 2. ed. São Paulo: EDUSP, 2011.

FURTADO, C. Análise do modelo brasileiro. Rio de Janeiro: Civilização Brasileira, 1972.

GORDON, L. O Progresso pela aliança. Rio de Janeiro: Record, 1962.

HOBSBAWM, E. A era dos extremos. 2. ed. São Paulo: Schwarcz, 1994.

IANNI, O. O colapso do populismo no Brasil. 3. ed. Rio de Janeiro: Civilização Brasileira, 1975.

MULLER, M. T. A lousa e o torno: a escola SENAI Roberto Mange, de Campinas. 2008. 334f. Tese (Doutorado em) - Universidade Estadual de Campinas, Campinas/SP, 2008. 
NOGUEIRA. F. M. G. A ajuda externa para a educação brasileira na produção do mito do desenvolvimento: da USAID ao BIRD. 1998. 187f. Tese (Doutorado em Educação) - Faculdade de Educação, Universidade Estadual de Campinas, Campinas, 1988. Disponível em: http://www.repositorio.unicamp.br/handle/REPOSIP/251293. Acesso em: 13 abr. 2020.

PICHELI, V. O IDORT enquanto proposta educacional no contexto de formação da hegemonia burguesa no Brasil (1930 - 1944). 1997. 143f. Dissertação (Mestrado em Educação) - Faculdade de Educação, Universidade Estadual de Campinas, Campinas, 1997.

PORTO, W. C. 1937. 3. ed. Brasília: Senado Federal, Subsecretaria de edições técnicas, 2012. Disponível em:

https://www2.senado.leg.br/bdsf/bitstream/handle/id/137571/Constituicoes_Brasileiras_v4_1 937.pdf?sequence=9. Acesso em: 06 abr. 2020. (Constituições brasileiras, v.4).

REVISTA IDORT. Pela cooperação. n.2, p.1-2, fev. 1932b.

REVISTA IDORT. Esprit de corps. n.4, p.1-3, abr. 1932c.

SAMPAIO JUNIOR, P. A. Furtado e os limites da razão burguesa na periferia do capitalismo. Revista da Universidade Federal de Uberlândia, Uberlândia: v.22, n.2, p.1-44, 2008.

USAID. Aliança para o progresso: recursos humanos para o desenvolvimento. Rio de Janeiro: Fundação Getúlio Vargas, 1965.

Recebido em abril 2021.

Aprovado em setembro 2021. 